Research Article

\title{
Two Kinds of Hydrogen Monomers Manifested in Plasma-Exposed Silicon
}

\author{
Vladimir V. Voronkov (D) \\ SunEdison Semiconductor-Global Wafers, via Nazionale 59, 39012 Merano, Italy \\ Correspondence should be addressed to Vladimir V. Voronkov; vvoronkov@gw-semi.com
}

Received 26 March 2018; Accepted 19 September 2018; Published 11 October 2018

Academic Editor: Claudio Pettinari

Copyright (C) 2018 Vladimir V. Voronkov. This is an open access article distributed under the Creative Commons Attribution License, which permits unrestricted use, distribution, and reproduction in any medium, provided the original work is properly cited.

\begin{abstract}
In boron-doped silicon annealed in a plasma ambient $\left(\right.$ at $\left.150^{\circ} \mathrm{C}\right)$, the reported hydrogen concentration profile and the hole profile cannot be simultaneously fitted assuming only one kind of in-diffusing hydrogen ions $\mathrm{H}^{+}$of a definite parameter $D^{+} K\left(\right.$ where $D^{+}$is the diffusivity of $\mathrm{H}^{+}$and $\mathrm{K}$ is the equilibrium dissociation constant of the $\mathrm{HB}$ defect, the passivated boron). A good fit is possible only assuming two independent kinds of $\mathrm{H}^{+}$- one of a larger value of $D^{+} K$ and the other-of a smaller value. A concept of two independent atomic subsystems $\mathrm{H}(1)$ and $\mathrm{H}(2)$, each involving both positive and neutral charge states, is also useful to account for hydrogen pairing into dimers.
\end{abstract}

\section{Introduction}

Hydrogen impurity plays an important role in silicon materials-by passivating dopants and other defects [1-6]. In p-type and near-intrinsic Si, under equilibrium conditions, the dominant monomeric state of hydrogen is thought [7] to be $\mathrm{H}^{+}(\mathrm{BC})$ - a positive ion in a bond-centred position. The acceptors (normally, boron $\mathrm{B}^{-}$) are passivated by combining $\mathrm{H}^{+}$and $\mathrm{B}^{-}$into neutral defects $\mathrm{HB}$. The data on hydrogen diffusion from a plasma ambient and on the related boron passivation were collected years ago, but they are still waiting for a proper analysis, in view of a growing interest to hydrogen as a powerful and promising tool to control the defects in Si.

The degree of passivation - a ratio of passivated boron concentration $[\mathrm{HB}]$ and nonpassivated boron concentration $\left[\mathrm{B}^{-}\right]$- is controlled by the concentration $\left[\mathrm{H}^{+}\right]$of free (nontrapped) hydrogen ions and the equilibrium dissociation constant $K$ of the $\mathrm{HB}$ defect:

$$
\frac{\left[\mathrm{H}^{+}\right]\left[\mathrm{B}^{-}\right]}{[\mathrm{HB}]}=K(T) \text {. }
$$

A depth profile of hydrogen concentration $C(z)$ includes a near-surface narrow region of a high concentration, and a bulk part where hydrogen is represented by free and trapped atomic species, $\mathrm{H}^{+}$and $\mathrm{HB}$. The concentration $\left[\mathrm{H}^{+}\right]$ turns out $[8]$ to be much smaller than $[\mathrm{HB}]$ or $\left[\mathrm{B}^{-}\right]$. The shape of the $C(z)$ profile, for a specified hydrogen concentration at the sample surface, depends [8] on a single material parameter $D^{+} K$ where $D^{+}$is the diffusivity of $\mathrm{H}^{+}$. The value of $D^{+} K$ based on the reported $C(z)$ profiles is about $6.5 \times 10^{4} \mathrm{~cm}^{-1} \mathrm{~s}^{-1}$ at $150^{\circ} \mathrm{C}$ being slightly different for different samples.

For one of the samples annealed at $150^{\circ} \mathrm{C}$ [9], also the hole profile $p(z)$ is available along with $C(z)$. Quite unexpectedly, fitting the $p(z)$ profile (described in the next section) gives an essentially smaller value of $D^{+} K$-about $10^{4} \mathrm{~cm}^{-1} \mathrm{~s}^{-1}$

This seeming discrepancy is resolved if there are two independently diffusing hydrogen ions that we denote $\mathrm{H}^{+}(1)$ and $\mathrm{H}^{+}(2)$ - one of a larger $D^{+} K$ and the other of a smaller $D^{+} K$. In the present paper, a theory of boron passivation by two independent ions $\mathrm{H}^{+}(1)$ and $\mathrm{H}^{+}(2)$ is considered and applied to fit some representative experimental profiles.

\section{Fitting Hole Profile with One Kind of $\mathbf{H}^{+}$}

For a sample of a doping level $N_{\mathrm{B}}=5 \times 10^{18} \mathrm{~cm}^{-3}$ annealed at $150^{\circ} \mathrm{C}$ for $30 \mathrm{~min}$, both the concentration profile $C(z)$ by SIMS (using the deuterium isotope of hydrogen) and the 
spreading resistance profile $R(z)$ were reported [9]. The resistance normalized by its bulk value $R_{\mathrm{b}}$ is equal to the normalized specific resistivity $\rho(z) / \rho_{\mathrm{b}}$. With the known bulk resistivity $\rho_{\mathrm{b}}$, the resistivity profile $\rho(z)$ is defined and converted into $p(z)$ using a standard ASTM procedure. This $p(z)$ profile is shown in Figure 1 by circles. The concentration profile $C(z)$ for the same sample is displayed in Figure 2(a).

Since $p=\left[\mathrm{B}^{-}\right]-\left[\mathrm{H}^{+}\right]$and $\mathrm{C}=[\mathrm{HB}]+\left[\mathrm{H}^{+}\right]$, the two profiles $p(z)$ and $C(z)$ are complementary: their sum is a fixed total boron concentration $N_{\mathrm{B}}$. The profiles can be simulated [8] by solving an equation for diffusion and drift of $\mathrm{H}^{+}$accompanied by fast trapping and detrapping of $\mathrm{H}^{+}$by boron, which maintains the equilibrium relation (1) between the reacting species. The solution depends on the value of $D^{+} \mathrm{K}$ and on the concentration of $\mathrm{H}^{+}$at the sample surface normalized by $K$; this ambient-controlled boundary parameter, $\left[\mathrm{H}^{+}\right] / K$, is denoted $X$.

In Figure 1(a), the curve 1 was calculated with $D^{+} K=8$ $\times 10^{4} \mathrm{~cm}^{-1} \mathrm{~s}^{-1}$ - the value deduced by fitting the concentration profile of Figure 2(a). The boundary parameter $X$ was set to 21.2 to reproduce the penetration depth of hydrogen, $0.57 \mu \mathrm{m}$. Clearly, the computed curve is inconsistent with the experimental hole profile. A much better (although not quite satisfactory) fit is achieved with an essentially smaller value of $D^{+} K=1.4 \times 10^{4} \mathrm{~cm}^{-1} \mathrm{~s}^{-1}$ and a larger $X=115$ (the curve 2 in Figure 1(a)). This smaller value of $D^{+} K$ is however inconsistent with the shape of the $C(z)$ profile in Figure 2(a).

\section{A Concept of Two Kinds of $\mathbf{H}^{+}$Ions}

To resolve this contradiction, we note that the information contained in the $C(z)$ and $p(z)$ profiles actually refers to different parts of the profiles.

The $C(z)$ bulk profile is comprised of a plateau portion (marked P in Figure 2(a)) and a tail portion (marked T). In the plateau, a small difference between $C$ and $N_{\mathrm{B}}$ cannot be accurately determined, and the informative part of the profile is only the tail. Therefore, the deduced $D^{+} K$ parameter refers to the hydrogen ions within the tail.

For the $p(z)$ profile, the nonpassivated boron concentration $\left[\mathrm{B}^{-}\right]$is directly defined in the whole in-diffused region, allowing to find $\mathrm{D}^{+} \mathrm{K}$ for the $\mathrm{H}^{+}$ions within the plateau.

It can be thus concluded that there are actually two independent passivating hydrogen ions: $\mathrm{H}^{+}(1)$ of a larger $D^{+} K$ dominating in the tail portion of the presently discussed hydrogen profile, and $\mathrm{H}^{+}(2)$ of a smaller $D^{+} K$ dominating in the plateau part. The first one is assumed to be the abovementioned bond-centred ion $\mathrm{H}^{+}(\mathrm{BC})$. The second one is in a different lattice location to be discussed later. Independent diffusion of these two species implies that there is a high energy barrier for transition from one state of $\mathrm{H}^{+}$to the other which prevents equilibration between them.

The concentration ratio of the two species $\mathrm{H}^{+}(1)$ and $\mathrm{H}^{+}(2)$ at the sample surface depends on the plasma ambient, and it can have a strongly nonequilibrium value. It is thus possible that the $\mathrm{H}^{+}(2)$ species is more significant under plasma exposure than under the equilibrium conditions.

The hydrogen in-diffusion and resulting boron passivation should be now reconsidered taking into account simultaneous presence of two kinds of $\mathrm{H}^{+}$ions.

\section{Boron Passivation by Two Independent In- Diffusing $\mathrm{H}^{+}$Ions}

The inferred existence of two independent $\mathrm{H}^{+}$ions is most essential for a plasma-induced acceptor (boron) passivation. In this case, there are two different structural forms of passivated boron $\mathrm{HB}$ : the $\mathrm{HB}(1)$ originates from trapping $\mathrm{H}^{+}(1)$, and $\mathrm{HB}(2)$ from trapping $\mathrm{H}^{+}(2)$. A transport equation of Reference [8] is applicable to each of the two $\mathrm{H}^{+} / \mathrm{HB}$ subsystems:

$$
\frac{\partial[\mathrm{HB}(\mathrm{I})]}{\partial t}=\frac{-\partial J(\mathrm{I})}{\partial z}
$$

where the flux $J(\mathrm{I})=-\mathrm{D}^{+}(\mathrm{I}) p \frac{\partial\left(\left[\mathrm{H}^{+}(\mathrm{I})\right] / p\right)}{\partial z}$.

The subsystem index I is either 1 or 2 . The concentration $[\mathrm{HB}(\mathrm{I})]$ in the left-hand part represents the total concentration for the subsystem I, neglecting a small contribution of free ions [8]. The flux $J(\mathrm{I})$ in Equation (2) includes a drift of positive hydrogen ions in the electric field related to a nonuniformity in $p(z)$. The concentration $\left[\mathrm{H}^{+}(1)\right]$ or $\left[\mathrm{H}^{+}(2)\right]$ of free ions is expressed through the major concentrations $[\mathrm{HB}(1)]$ or $[\mathrm{HB}(2)]$ using Equation (1) - now applied to each species:

$$
\left[\mathrm{H}^{+}(\mathrm{I})\right]=\frac{\mathrm{K}(\mathrm{I})[\mathrm{HB}(\mathrm{I})]}{\left[\mathrm{B}^{-}\right]} .
$$

After that, each of the two transport equations (2) contains only one parameter, either $D^{+}(1) K(1)$ or $D^{+}(2) K(2)$. At $150^{\circ} \mathrm{C}, D^{+}(1) K(1)$ is already defined to be $8 \times 10^{4} \mathrm{~cm}^{-1} \mathrm{~s}^{-1}$ while $D^{+}(2) K(2)$ is on the order of $10^{4} \mathrm{~cm}^{-1} \mathrm{~s}^{-1}$, and only a small adjustment of this parameter is required; the best-fit value was found to be $D^{+}(2) K(2)=9.6 \times 10^{3} \mathrm{~cm}^{-1} \mathrm{~s}^{-1}$.

The hole concentration $p=\left[\mathrm{B}^{-}\right]-\left[\mathrm{H}^{+}(1)\right]-\left[\mathrm{H}^{+}(2)\right]$ is close to that of nonpassivated boron $\left[\mathrm{B}^{-}\right]$:

$$
p=\left[\mathrm{B}^{-}\right]=N_{\mathrm{B}}-[\mathrm{HB}(1)]-[\mathrm{HB}(2)] .
$$

This is the only equation through which one subsystem affects the other.

The diffusion problem involves two ambient-dependent boundary parameters $X(1)=\left[\mathrm{H}^{+}(1)\right] / K(1)$ and $X(2)=\left[\mathrm{H}^{+}(2)\right] / K(2)$. The surface value of $\left[\mathrm{B}^{-}\right]$is expressed through these parameters from Equations (4) and (3): $\left[\mathrm{B}^{-}\right]=N_{\mathrm{B}} /(1+X(1)+X(2))$.

The best fit of the hole profile is shown by the solid curve in Figure 1(b), computed with $X(1)=4.3$ and $X(2)=134$. This curve reproduces the measured $p(z)$ profile much better than the curves 1 and 2 in Figure 1(a), which are based on only one kind of $\mathrm{H}^{+}$ion.

The computed concentration profile $C(z)$-for the parameter set specified above-is shown by the solid curve in Figure 2(a). The reported hydrogen penetration depth [9] 


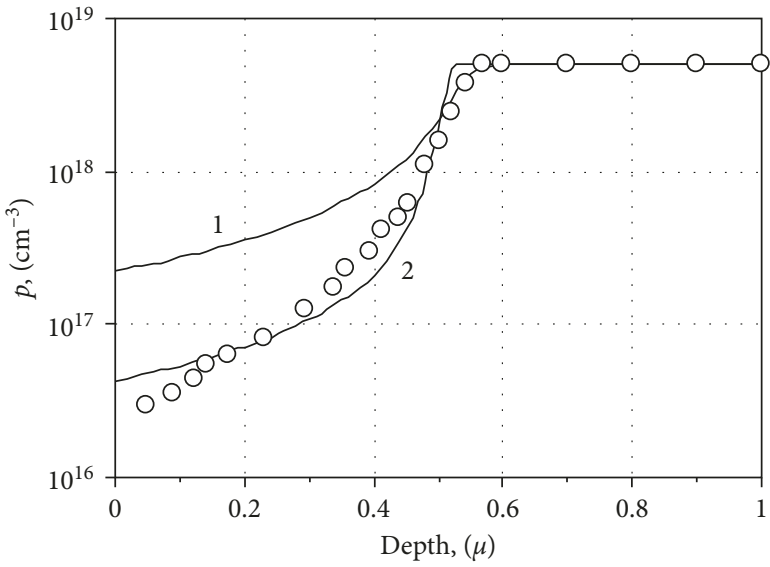

(a)

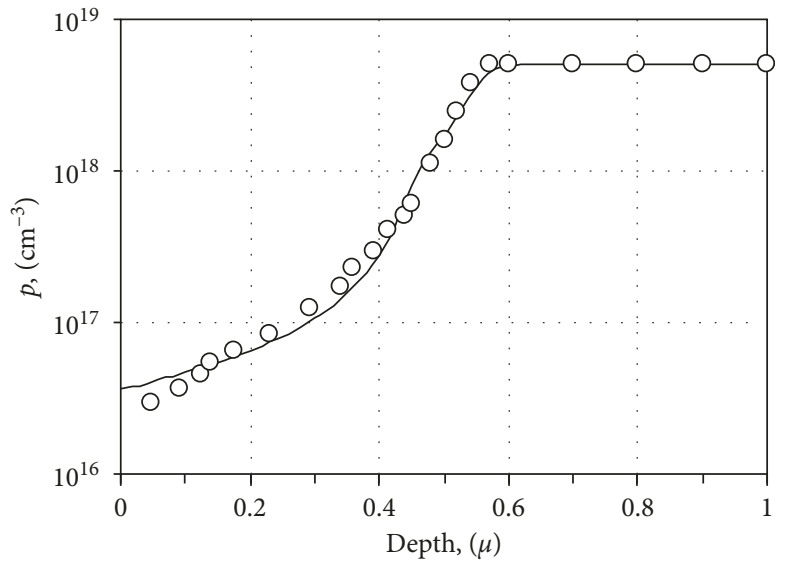

(b)

FIgURE 1: Hole depth profile in a sample of $N_{\mathrm{B}}=5 \times 10^{18} \mathrm{~cm}^{-3}$ annealed at $150^{\circ} \mathrm{C}$ for $30 \mathrm{~min}$. (a) Fitting by in-diffusion of one kind of $\mathrm{H}^{+}$. Curve 1: with $D^{+} K=8 \times 10^{4} \mathrm{~cm}^{-1} \mathrm{~s}^{-1}, X=21.2$; curve 2: with $D^{+} K=1.4 \times 10^{4} \mathrm{~cm}^{-1} \mathrm{~s}^{-1}, X=115$. (b) Fitting by in-diffusion of two kinds of $\mathrm{H}^{+}$ with the parameters specified in the text.

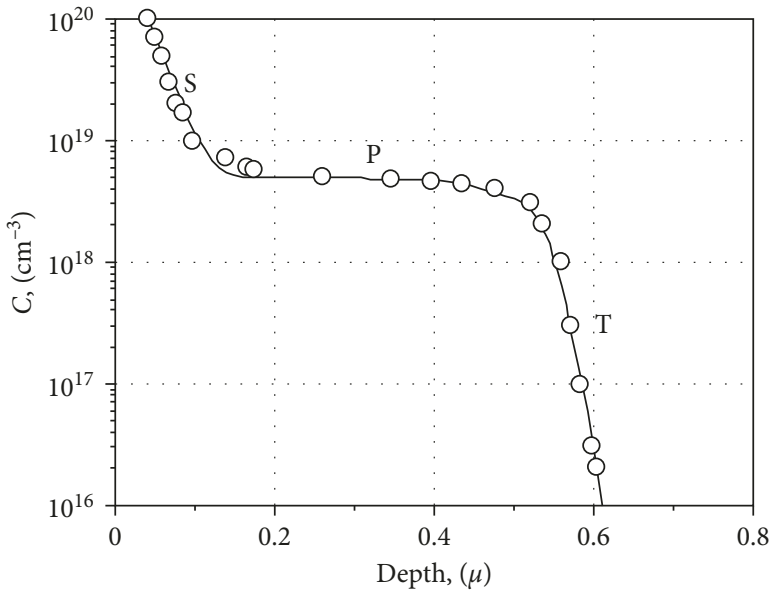

(a)

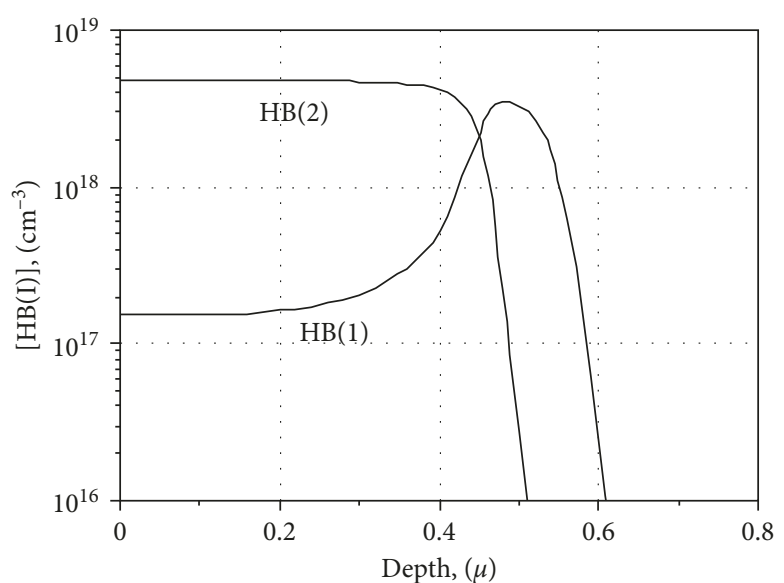

(b)

Figure 2: Concentration profiles for the sample of Figure 1. (a) Solid curve is computed for the same parameters that were used in Figure 1(b), and the experimental points (circles) are rescaled to match the experimental penetration depth by Figure 1. (b) Individual components of the passivated boron.

was a bit larger for the $C(z)$ profile in comparison with the $p(z)$ profile. This small discrepancy may be due to some inaccuracy in a crater depth $z$ in the SIMS technique, and it was adjusted by rescaling the experimental $C(z)$ profile-by multiplying all the values of $z$ by a scaling factor 0.86 . This rescaled profile-shown in Figure 2(a) by the circles-is well consistent with the predicted profile, the solid curve.

The near-surface high-concentration region (marked $S$ in Figure 2(a)) was modelled here as in-diffusion of slow hydrogen dimers $\mathrm{H}_{2 \mathrm{C}}$ [10] produced at the surface. The concentration profile of dimers is described by an erfc function with an apparent diffusivity $3 \times 10^{-15} \mathrm{~cm}^{2} / \mathrm{s}$, which is close to that expected for $\mathrm{H}_{2 \mathrm{C}}$ [10]. The dimeric contribution $2\left[\mathrm{H}_{2 \mathrm{C}} \mathrm{C}\right.$ is simply added to that resulting from indiffusion and trapping of $\mathrm{H}^{+}(1)$ and $\mathrm{H}^{+}(2)$.

To illustrate a specific effect of a simultaneous transport of two $\mathrm{H}^{+} / \mathrm{HB}$ subsystems, the two components of the passivated boron, $[\mathrm{HB}(1)]$ and $[\mathrm{HB}(2)]$, are shown separately in Figure 2(b). The $\mathrm{HB}(2)$ dominates in the major part of the passivated region, while $\mathrm{HB}(1)$ dominates within the tail portion. A qualitative explanation is that the species $\mathrm{H}^{+}(2)$, due to a large $X(2)=\left[\mathrm{H}^{+}(2)\right] / K(2)$, occupy the major part of boron traps down to some depth, while the $\mathrm{H}^{+}(1)$ species, facing a low concentration of remaining $\mathrm{B}^{-}$traps, easily penetrate to a larger depth and thus control the tail part of the profile.

\section{Fitting Concentration Profile for Lower Doping Level}

Another example of a concentration profile with a wellresolved tail $\left(N_{\mathrm{B}}=10^{17} \mathrm{~cm}^{-3}\right.$, annealed at $150^{\circ} \mathrm{C}$ for $30 \mathrm{~min}$ [11]), is shown in Figure 3(a). A peculiarity of this profile is a relatively wide S-component (in comparison with Figure 2(a)) spreading down to a micron. This scale is consistent with 


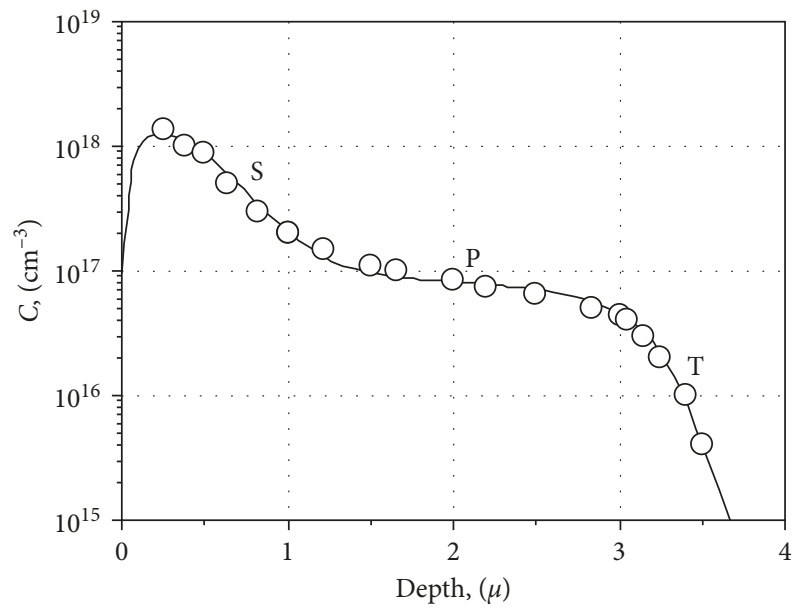

(a)

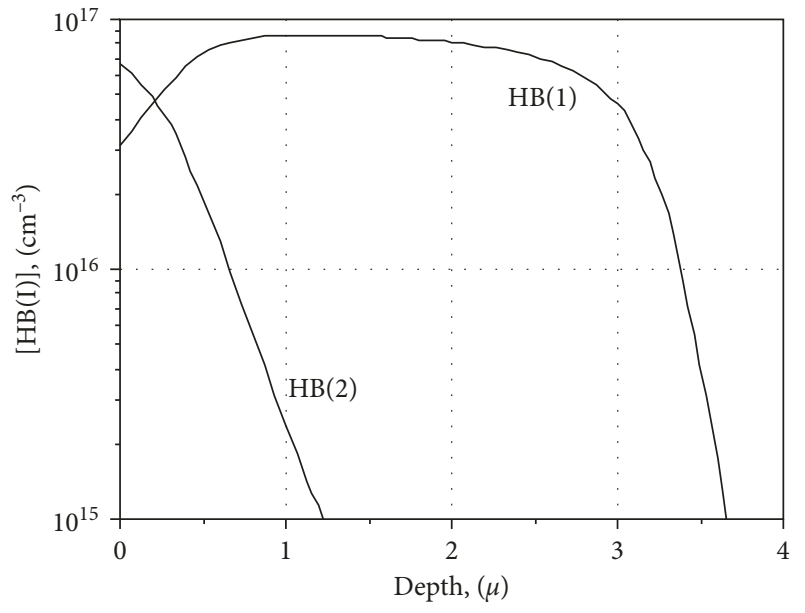

(b)

FIgUre 3: Concentration profiles for a sample of $N_{\mathrm{B}}=10^{17} \mathrm{~cm}^{-3}$ annealed at $150^{\circ} \mathrm{C}$ for $30 \mathrm{~min}$ [11]. (a) Total concentration due to boron passivation and formation of $\mathrm{H}_{2 \mathrm{~A}}$ dimers by $\mathrm{H}^{0}(1)+\mathrm{HB}(2)$. (b) Individual components of the passivated boron.

a diffusion length of $\mathrm{H}_{2 \mathrm{~A}}$ dimers-moderately mobile species observed in samples saturated with hydrogen at high $T$ and subsequently quenched $[12,13]$. This kind of dimers is formed by a pairing reaction $\mathrm{H}^{0}(1)+\mathrm{H}^{+}(1)$ at a known rate [10]; the neutral monomer $\mathrm{H}^{0}(1)$ is a minor but extremely fast species located in a tetrahedral interstice. However, the computed concentration $\left[\mathrm{H}_{2 \mathrm{~A}}\right]$, due to this pairing reaction, turns out to be much smaller than $N_{\mathrm{B}}[8]$ and cannot account for the S-component.

Now, with two independent subsystems of monomeric hydrogen, more pairing reactions can proceed involving $\mathrm{H}^{0}(1)$ and $\mathrm{H}^{+}(2)$ or $\mathrm{HB}(2)$ and these ones can be more efficient. The reaction $\mathrm{H}^{0}(1)+\mathrm{HB}(2)$ seems preferable since $[\mathrm{HB}(2)]$ is much larger than $\left[\mathrm{H}^{+}(2)\right]$. The diffusion-limited pairing rate is $4 \pi r D^{0}(1)\left[\mathrm{H}^{0}(1)\right][\mathrm{HB}(2)]$ where $r$ is the capture (pairing) radius, conventionally assumed to be $0.5 \mathrm{~nm}$. The ratio $\left[\mathrm{H}^{+}(1)\right] /\left[\mathrm{H}^{0}(1)\right]$ equals $p / p_{\mathrm{d}}(1)$ where $p_{\mathrm{d}}(1)$ is the characteristic hole concentration for the Fermi level coincident with the donor level for the $\mathrm{H}^{0}(1)$ to $\mathrm{H}^{+}(1)$ transition. Using Equation (3), the pairing rate is expressed through the two major concentrations $[\mathrm{HB}(1)]$ and $[\mathrm{HB}(2)]$ :

$$
G=\frac{\beta[\mathrm{HB}(1)][\mathrm{HB}(2)]}{p^{2}},
$$

where the pairing kinetic coefficient $\beta$, for the diffusionlimited reaction, is

$$
\beta=4 \pi r \mathrm{D}^{0}(1) p_{\mathrm{d}}(1) \mathrm{K}(1) .
$$

The actual value of $\beta$ can be smaller, and it should be treated as a fitting parameter with the upper limit given by Equation (6). All the parameters in Equation (6) were specified [8], and the upper limit for $\beta$ is $6 \times 10^{12} \mathrm{~cm}^{-3} \mathrm{~s}^{-1}$ at $150^{\circ} \mathrm{C}$.

The dimeric concentration $\left[\mathrm{H}_{2 \mathrm{~A}}\right]$ is incremented at a rate $G$, while each concentration $[\mathrm{HB}(1)]$ and $[\mathrm{HB}(2)]$ is diminished at the same rate $G$. Each transport equation (2) is thus modified by adding a term $G$ in the right-hand part.
The equation set now includes also a diffusion equation for produced $\mathrm{H}_{2 \mathrm{~A}}$ dimers:

$$
\frac{\partial\left[\mathrm{H}_{2 \mathrm{~A}}\right]}{\partial \mathrm{t}}=D_{2 \mathrm{~A}} \frac{\partial^{2}\left[\mathrm{H}_{2 \mathrm{~A}}\right]}{\partial \mathrm{z}^{2}}+G
$$

Backward dissociation of $\mathrm{H}_{2 \mathrm{~A}}$ into $\mathrm{H}^{0}(1)+\mathrm{HB}(2)$ proceeds by $\mathrm{H}_{2 \mathrm{~A}}+\mathrm{B}^{-}+\mathrm{h}^{+}$at a rate proportional to $p^{2}$. It is neglected at a relatively low temperature of $150^{\circ} \mathrm{C}$ and a moderate hole concentration.

To reproduce the $C(z)$ profile in Figure 3(a), we use for $D^{+}(2) K(2)$ the previously deduced value, $9.6 \times 10^{3} \mathrm{~cm}^{-1} \mathrm{~s}^{-1}$. The parameter $D^{+}(1) K(1)$ was a bit reduced, down to $5 \times$ $10^{4} \mathrm{~cm}^{-1} \mathrm{~s}^{-1}$, for a better reproduction of the tail. The diffusivity $D_{2 \mathrm{~A}}$ of $\mathrm{H}_{2 \mathrm{~A}}$ dimer is known $[10,14,15]$ to be $2 \times 10^{-13} \mathrm{~cm}^{2} / \mathrm{s}$ at $150^{\circ} \mathrm{C}$ (for the deuterium isotope). The remaining parameters are the two boundary ratios $X(1)$ and $X(2)$, and the pairing coefficient $\beta$; their fitted values are $X(1)=10.3, X(2)=21.7$ and $\beta$ $=4 \times 10^{12} \mathrm{~cm}^{-3} \mathrm{~s}^{-1}$. The latter value is only slightly smaller than the upper limit of $6 \times 10^{12} \mathrm{~cm}^{-3} \mathrm{~s}^{-1}$. The corresponding best-fit profile is shown by the solid curve in Figure 3(a). The computed depth dependence of the pairing rate shows that the $\mathrm{H}_{2 \mathrm{~A}}$ dimers are produced within a near-surface zone of about $0.3 \mu \mathrm{m}$; they out-diffuse to the surface and in-diffuse into the sample bulk.

For illustration, also the individual profiles of $\mathrm{HB}(1)$ and $\mathrm{HB}(2)$ are displayed in Figure 3(b). Here, the hydrogen species of the second subsystem are spent on pairing near the surface, and they do not penetrate deep into the bulk. The bulk part of the profile is occupied mostly by $\mathrm{HB}(1)$.

The ratio of $\left[\mathrm{H}_{2 \mathrm{~A}}\right]$ and $[\mathrm{HB}(2)]$ is proportional to $[\mathrm{HB}$ (1)] $/ p^{2}$, by Equation (5). It is relatively large for the case of Figure 3(a) but becomes reduced at a higher doping level $N_{\mathrm{B}}$ (a higher $p$ ). Besides, the dissociation of $\mathrm{H}_{2 \mathrm{~A}}$ may become significant at a higher $p$. For this reason, the profiles in Figures 1 and 2 (computed with a neglected pairing) are hardly changed when recalculated including the pairing.

Another example, for the same doping level $N_{\mathrm{B}}=$ $10^{17} \mathrm{~cm}^{-3}$ and the same annealing temperature $150^{\circ} \mathrm{C}$, taken 


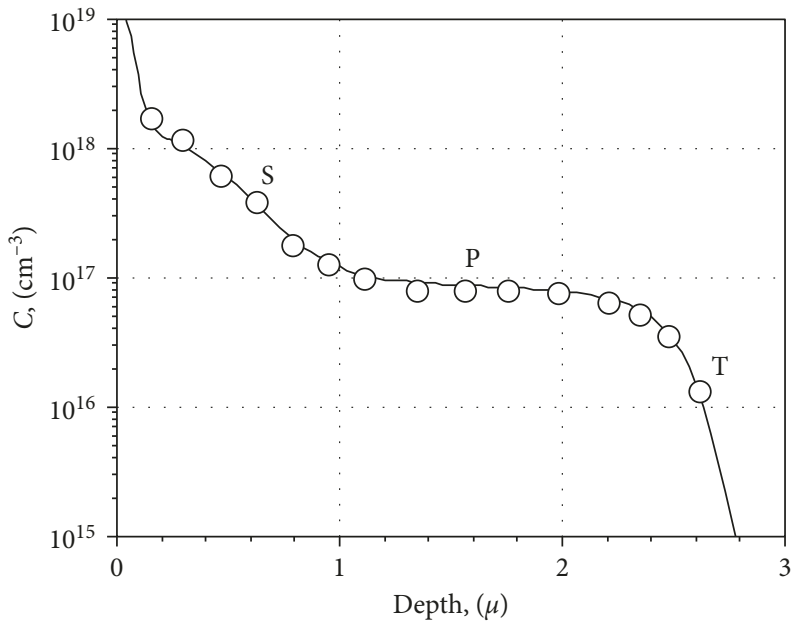

(a)

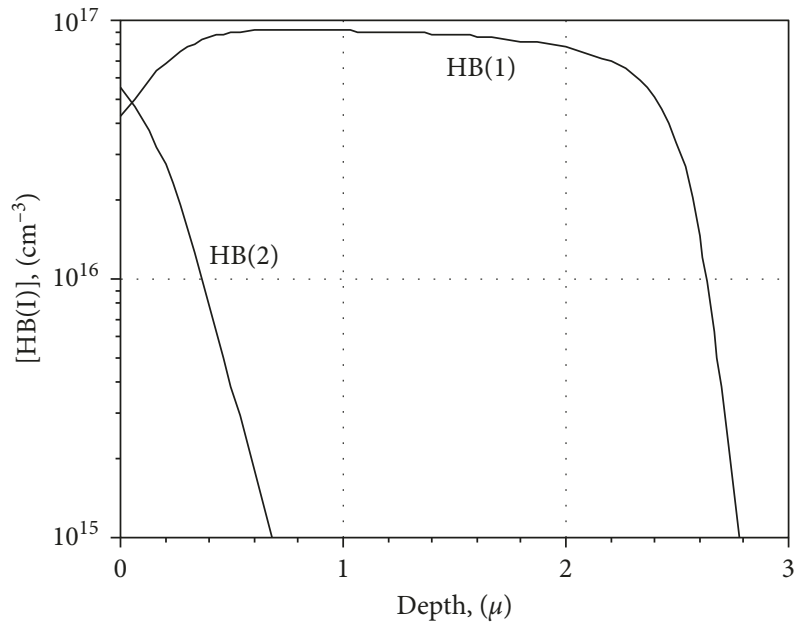

(b)

Figure 4: Concentration profiles for a sample of $N_{\mathrm{B}}=10^{17} \mathrm{~cm}^{-3}$ annealed at $150^{\circ} \mathrm{C}$ for $2 \mathrm{~h}$ [16]. (a) Total concentration due to boron passivation and formation of $\mathrm{H}_{2 \mathrm{~A}}$ dimers by $\mathrm{H}^{0}(1)+\mathrm{HB}(2)$. (b) Individual components of the passivated boron.

from Reference [16], is shown in Figure 4(a). This profile has quite a similar shape but the width of the S-component corresponds to a smaller diffusivity $D_{2 \mathrm{~A}}$, and the tail is relatively steep corresponding to a smaller $D^{+}(1) K(1)$. This is understood if, in spite of the same nominal temperature for the profiles of Figures 3(a) and 4(a), the actual temperature is somewhat lower (roughly, by $15^{\circ} \mathrm{C}$ ) for the latter case. To fit the tail of the profile of Figure 4(a), the parameter $D^{+}(1) K(1)$ was reduced down to $10^{4} \mathrm{~cm}^{-1} \mathrm{~s}^{-1}$, and $D^{+}(2) K(2)$ was reduced by the same factor, down to $2 \times 10^{3} \mathrm{~cm}^{-1} \mathrm{~s}^{-1}$. The other parameters $\left(\beta, D_{2 \mathrm{~A}}, X(1)\right.$ and $\left.X(2)\right)$ were set to achieve the best fit: $\beta=2 \times 10^{12} \mathrm{~cm}^{-3} \mathrm{~s}^{-1}, D_{2 \mathrm{~A}}=8 \times 10^{-14} \mathrm{~cm}^{2} / \mathrm{s}, X(1)=$ 14.5, $X(2)=18.7$. A narrow near-surface part of the S-component in Figure 4(a) was modelled, like in Figure 2(a) by in-diffusion of slow dimers $\mathrm{H}_{2 \mathrm{C}}$.

The individual contributions of $\mathrm{HB}(1)$ and $\mathrm{HB}(2)$ into boron passivation are shown in Figure 4(b); these profiles are similar to those of Figure 3(b): the bulk is dominated by HB (1) species.

\section{In-Diffusion Profiles in Lightly Doped n-Si}

In lightly doped $\mathrm{n}-\mathrm{Si}$, the observed concentration profiles $C(z)$ include a near-surface component (labelled S) and a bulk component (labelled B). Two representative examples $[3,17]$ are shown in Figure 5. The profile is insensitive to variations in the electron concentration suggesting that it is formed by neutral hydrogen species while $\mathrm{H}^{+}$is not now essential. Each component is well described as resulting from pairing of some in-diffusing species of a diffusivity $D$ at a rate

$$
G=4 \pi r D c^{2}
$$

where $c(z)$ is a steady-state depth profile of the in-diffusing species and $r$ is the capture (pairing) radius. With a variable $S=D c$ used instead of $c$, the depth profile obeys a simple equation:

$$
\frac{d^{2} S}{d z^{2}}=2 G=\left(\frac{8 \pi r}{D}\right) S^{2} .
$$

The solution of Equation (9) depends on one material parameter $D / r$ and one boundary parameter $S_{0}$-a surface value of $S(z)$ :

$$
S(z)=\frac{S_{0}}{(1+z / L)^{2}} .
$$

The characteristic penetration depth $L$ equals $\left[(D / r) /\left(4 \pi S_{0} / 3\right)\right]^{1 / 2}$.

The total hydrogen concentration $C(z)$ is mostly due to produced pairs of in-diffusing defects (while a contribution $c$ of the source species themselves is negligible [8]). The diffusion of produced pairs is neglected on the time and depth scales of the profiles; then,

$$
C(z)=2 G(z) t=\frac{\left(2 G_{0} t\right)}{(1+z / L)^{4}} .
$$

With the deduced shape parameters $L$ and $G_{0}$, the ratio $D / r$ is calculated as $(4 \pi / 9) G_{0} L^{4}$.

For the S-component, the deduced ratio $D / r$ [8] is close to the value expected for a hydrogen species responsible for a slow stage of tritium loss at 400 to $500^{\circ} \mathrm{C}$ [18] - from samples saturated with the tritium isotope at high $T$ and quenched. The diffusivity of this mysterious species is much higher than $D_{2 \mathrm{~A}}$ but much smaller than the known atomic hydrogen diffusivity [19], and this species was tentatively identified [10] as a "fast dimer" $\mathrm{H}_{2 \mathrm{~B}}$. Accordingly, the $S$-component was attributed to $\mathrm{H}_{2 B}$ pairing into tetramers. An alternative treatment is possible, but it will not be discussed in the present paper. Regarding the B-component, there were two difficulties [8]:

(1) The value of $D / r$ for this component was orders of magnitude smaller than the value of $D / r$ for the neutral tetrahedral monomer $\mathrm{H}^{0}(1)$. 


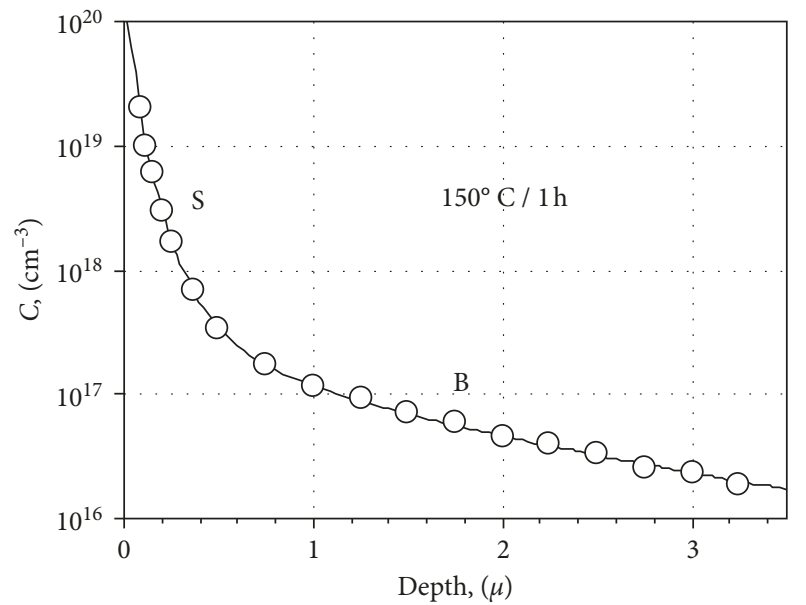

(a)

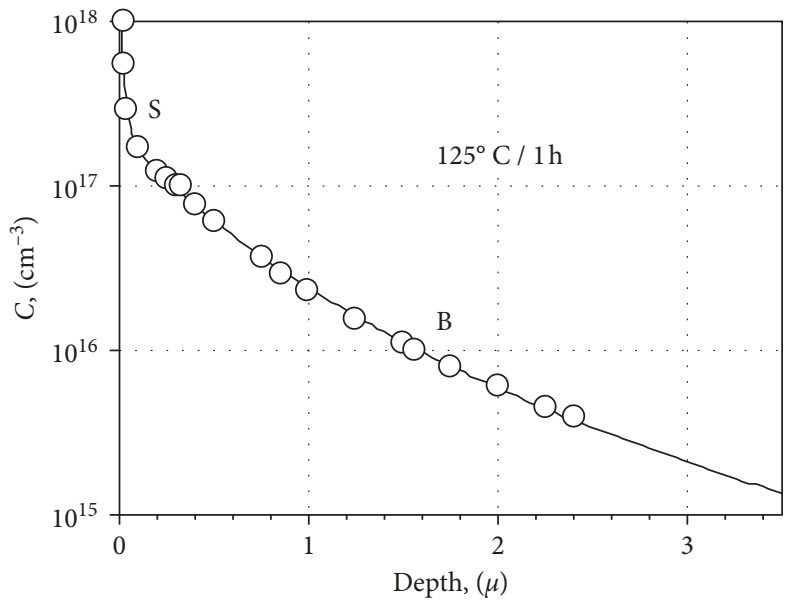

(b)

Figure 5: Concentration profiles in lightly doped n-Si. (a) Annealing at $150^{\circ} \mathrm{C}$ for $1 \mathrm{~h}$ [3]. (b) Annealing at 125 $\mathrm{C}$ for $1 \mathrm{~h}$ [17]. Each component of a profile, $\mathrm{S}$ and $\mathrm{B}$, is described by Equation (11).

(2) The deduced values of $D / r$ were strongly different for two close temperatures: $150^{\circ} \mathrm{C}$ (Figure $4(\mathrm{a}), \mathrm{D} / \mathrm{r}=$ $0.8 \mathrm{~cm} / \mathrm{s}$ ) and $125^{\circ} \mathrm{C}$ (Figure $4(\mathrm{~b}), D / r=0.015 \mathrm{~cm} / \mathrm{s}$ ). A huge difference-by a factor of 53-is too large for any reasonable temperature dependence of $D / r$.

Now, a concept of two different atomic subsystems offers a simple solution to these puzzles if we assume that $\mathrm{H}^{+}(2)$ is a part of a subsystem $\mathrm{H}(2)$ that includes also a neutral species $\mathrm{H}^{0}(2)$, dominating in intrinsic and n-type Si (which implies that the donor level of $\mathrm{H}(2)$ is below the midgap). The $\mathrm{B}$-component can be then ascribed to dimers produced by interpairing $\mathrm{H}^{0}(1)+\mathrm{H}^{0}(2)$ or self-pairing $\mathrm{H}^{0}(2)+\mathrm{H}^{0}(2)$. There are two extreme cases:

Case 1. The equilibration time between $\mathrm{H}^{0}(1)$ and $\mathrm{H}^{0}(2)$ is shorter than the anneal duration. Then, the two species coexist in the equilibrium ratio and diffuse together, as one species of an apparent diffusivity $D_{\mathrm{a}}$ averaged over the two species:

$$
D_{\mathrm{a}}=\frac{\left[D^{0}(1)+D^{0}(2) R_{21}\right]}{\left(1+R_{21}\right)},
$$

where $R_{21}$ is the equilibrium concentration ratio of $\mathrm{H}^{0}(2)$ and $\mathrm{H}^{0}(1)$. In the $D / r$ ratio deduced from the shape of the B-component, the apparent diffusivity $D$ is equal to $D_{\mathrm{a}}$. We assume that this situation is valid at a higher $T=150^{\circ} \mathrm{C}$-for the profile of Figure 5(a). With a diffusion-limited capture radius, $r=0.5 \mathrm{~nm}$, the diffusivity $D_{\mathrm{a}}=4 \times 10^{-8} \mathrm{~cm}^{2} / \mathrm{s}$. The diffusivity of atomic hydrogen [19] extrapolated down to $150^{\circ} \mathrm{C}$ is $1.4 \times 10^{-8} \mathrm{~cm}^{2} / \mathrm{s}$ (for the deuterium isotope). This diffusivity is averaged over all the atomic species present in intrinsic $\mathrm{Si}$, including the major one, $\mathrm{H}^{+}(1)$, and therefore it is smaller than $D_{\mathrm{a}}$ (which is averaged only over the neutral states). Yet, the difference between the two diffusivities is not very large showing that $\mathrm{H}^{0}(2)$ in intrinsic Si gives a small but significant contribution to the total concentration.
Case 2. The equilibration time is longer than the anneal duration. Then, the two species diffuse independent of each other. If, in addition, the concentration of $\mathrm{H}^{0}(1)$ is so small that interpairing can be neglected in comparison with self-pairing of $\mathrm{H}^{0}(2)$, then the apparent diffusivity $D$ will be identical to $D^{0}(2)$. This situation may hold at a lower temperature of $125^{\circ} \mathrm{C}$. Assuming again a diffusion-limited capture radius, $r=0.5 \mathrm{~nm}$, we specify the diffusivity of the neutral $\mathrm{H}^{0}(2)$ species at $125^{\circ} \mathrm{C}: D^{0}(2)=7.5 \times 10^{-10} \mathrm{~cm}^{2} / \mathrm{s}$. If a representative diffusivity prefactor, $0.01 \mathrm{~cm}^{2} / \mathrm{s}$ is further adopted, the migration energy of $\mathrm{H}^{0}(2)$ is estimated to be $0.56 \mathrm{eV}$. The $D^{0}(2)$ diffusivity extrapolated from $125^{\circ} \mathrm{C}$ to $150^{\circ} \mathrm{C}$ is then $2 \times 10^{-9} \mathrm{~cm}^{2} / \mathrm{s}$ - much smaller than the averaged diffusivity $D_{\mathrm{a}}$ deduced above to be $4 \times 10^{-8} \mathrm{~cm}^{2} / \mathrm{s}$. By Equation (12), it is concluded that the hydrogen transport at $150^{\circ} \mathrm{C}$ is mostly due to $\mathrm{H}^{0}(1)$, while the total concentration of the neutral species is mostly due to $\mathrm{H}^{0}(2)$. The expression (12) is then simplified to $D_{\mathrm{a}}=D^{0}(1) / R_{21}$.

A huge difference between the apparent diffusivities $D$ at 125 and $150^{\circ} \mathrm{C}$ is now attributed to a different meaning of the apparent diffusivity $D$ for these two cases: a relatively low diffusivity $D^{0}(2)$ at a lower $T$, and a much higher average diffusivity $D_{\text {a }}$ (enhanced by a contribution of fast $\mathrm{H}^{0}(1)$ species) at a higher $T$.

\section{Summary}

Penetration of $\mathrm{H}^{+}$hydrogen ions from a plasma ambient into a boron-doped sample is limited by their trapping by boron into HB neutral defects. It is controlled by the surface concentration of $\mathrm{H}^{+}$and by a single material parameter $\mathrm{D}^{+} \mathrm{K}$-a product of the $\mathrm{H}^{+}$diffusivity $\mathrm{D}^{+}$and the equilibrium dissociation constant $K$ of the HB defects. Under an assumption of only one kind of $\mathrm{H}^{+}$, of a definite value of $D^{+} K$, it is impossible to reproduce simultaneously the hydrogen concentration profile $C(z)$ and the hole profile $p(z)$ measured for the same sample at $150^{\circ} \mathrm{C}$ : the former can be well fitted 
only with a relatively large $D^{+} K$ while the latter can be roughly fitted only with a much smaller $D^{+} K$.

This difficulty is overcome by assuming two different kinds of $\mathrm{H}^{+}$ions, $\mathrm{H}^{+}(1)$ and $\mathrm{H}^{+}(2)$, one of a larger $D^{+} K$ and the other of a smaller $D^{+} K$. They in-diffuse-without an exchange between them-and get trapped by $\mathrm{B}^{-}$into two different kinds of passivated boron, $\mathrm{HB}(1)$ and $\mathrm{HB}(2)$. A transport of each species is affected by the presence of the other species through the hole concentration that depends on the total amount of passivated boron, $[\mathrm{HB}(1)]+[\mathrm{HB}(2)]$.

The deduced $D^{+} K$ at $150^{\circ} \mathrm{C}$ is about $6 \times 10^{4} \mathrm{~cm}^{-1} \mathrm{~s}^{-1}$ for $\mathrm{H}^{+}(1)$ and close to $10^{4} \mathrm{~cm}^{-1} \mathrm{~s}^{-1}$ for $\mathrm{H}^{+}(2)$. Relative contributions of the two species depend on their concentrations at the sample surface controlled by a composition of the ambient (hydrogen plasma). In one example, $\mathrm{H}^{+}(2)$ was found to be the major passivating species down to some depth, leaving a low concentration of nonoccupied boron traps. In that case, $\mathrm{H}^{+}(1)$ easily diffuse through the passivated region and control the hydrogen concentration within a tail of the profile.

In another example (at a lower doping level), the $\mathrm{H}^{+}(2)$ ions are spent on formation of hydrogen dimers and do not penetrate deep; the sample bulk is then dominated by the species of the first kind.

It is assumed that $\mathrm{H}^{+}(1)$ is an ion in the bond-centred position that is dominant under the equilibrium conditions in intrinsic $\mathrm{Si}$. This one is equilibrated with a minor but highly mobile neutral species $\mathrm{H}^{0}(1)$ in the tetrahedral location. Also, the $\mathrm{H}^{+}(2)$ species seems to be present along with a neutral state $\mathrm{H}^{0}(2)$, of a much higher concentration than $\mathrm{H}^{0}(1)$. In the early stage of discussing the hydrogen properties in $\mathrm{Si}$, it was argued that, due to its small size, a hydrogen atom should occupy a tetrahedral interstice remaining neutral. Now, we revive this notion assuming that the $\mathrm{H}^{0}(1)$ is actually an excited state of the neutral tetrahedral hydrogen while the ground state corresponds to $\mathrm{H}^{0}(2)$. There should be a high energy barrier for transition between these two states, which retards an exchange between them. The reported hydrogen profiles in lightly doped n-Si for 125 and $150^{\circ} \mathrm{C}$ suggest that the exchange is negligible at $125^{\circ} \mathrm{C}$ but relatively fast at $150^{\circ} \mathrm{C}$.

The hydrogen profiles normally include a near-surface part of a very high concentration. This "S-component" of a profile cannot be ascribed to the unique reason; it is specific for particular samples:

(i) In near-intrinsic $\mathrm{Si}$, the $\mathrm{S}$-component is clearly caused by self-pairing of some in-diffusing neutral species different from $\mathrm{H}^{0}(1)$ and $\mathrm{H}^{0}(2)$-presumably the fast hydrogen dimer $\mathrm{H}_{2 \mathrm{~B}}$. The true nature of this species is still to be established.

(ii) In samples moderately doped with boron, the S-component (relatively wide) can be attributed to formation of moderately mobile dimers $\mathrm{H}_{2 \mathrm{~A}}$ by interpairing reaction $\mathrm{H}^{0}(1)+\mathrm{HB}(2)$.

(iii) In heavily doped samples, the S-component is seemingly due to slow dimers $\mathrm{H}_{2 \mathrm{C}}$ that are formed at the surface (or close to the surface) and in-diffuse into the bulk.

\section{Conflicts of Interest}

The authors declare that they have no conflicts of interest.

\section{References}

[1] J. I. Pankove, R. O. Wance, and J. E. Berkeyheiser, "Neutralization of acceptors in silicon by atomic hydrogen," Applied Physics Letters, vol. 45, no. 10, pp. 1100-1102, 1984.

[2] S. J. Pearton, J. W. Corbett, and M. Stavola, Hydrogen in Crystalline Semiconductors, Springer, Berlin, Germany, 1991.

[3] C. Herring and N. M. Johnson, "Chapter 10 hydrogen migration and solubility in silicon," in Semiconductors and Semimetals, vol. 34, pp. 225-350, Academic Press, Inc, Cambridge, MA, USA, 1991.

[4] C. Herring, N. M. Johnson, and C. G. Van de Walle, "Energy levels of isolated interstitial hydrogen in silicon," Physical Review B, vol. 64, no. 12, article 125209, 2001.

[5] S. Wilking, C. Beckh, S. Ebert, A. Herguth, and G. Hahn, "Influence of bound hydrogen states on BO-regeneration kinetics and consequences for high-speed regeneration processes," Solar Energy Materials \& Solar Cells, vol. 131, pp. 2-8, 2014.

[6] N. Nampalli, B. J. Hallam, C. E. Chan, M. D. Abbot, and S. R. Wenham, "Influence of hydrogen on the mechanism of permanent passivation of boron-oxygen defects in p-type Czochralski silicon," IEEE Journal of Photovoltaics, vol. 5, no. 6, p. 1580, 2015.

[7] S. K. Estreicher, M. Stavola, and J. Weber, Silicon, Germanium, and their Alloys: Defects, Impurities and Nanocrystals, G. Kissinger and S. Pizzini, Eds., CRC Press, Boca Raton, FL, USA, Chapter 7, 2014.

[8] V. V. Voronkov and R. Falster, "Modelling plasma-induced hydrogen profiles in boron-doped and near-intrinsic silicon," Physica Status Solidi (a), vol. 214, no. 7, article 1700287, 2017.

[9] N. M. Johnson, "Mechanism for hydrogen compensation of shallow-acceptor impurities in single-crystal silicon," Physical Review B, vol. 31, no. 8, pp. 5525-5528, 1985.

[10] V. V. Voronkov and R. Falster, "Formation, dissociation, and diffusion of various hydrogen dimers in silicon," Physica Status Solidi (b), vol. 254, no. 6, article 1600779, 2017.

[11] N. M. Johnson, F. A. Ponce, R. A. Street, and R. J. Nemanich, "Defects in single-crystal silicon induced by hydrogenation," Physical Review B, vol. 35, no. 8, pp. 4166-4169, 1987.

[12] R. E. Pritchard, M. A. Ashwin, J. H. Tucker, and R. C. Newman, "Isolated interstitial hydrogen molecules in hydrogenated crystalline silicon," Physical Review B, vol. 57, no. 24, pp. R15048-R15051, 1998.

[13] R. E. Pritchard, J. H. Tucker, R. C. Newman, and E. C. Lightowlers, "Hydrogen molecules in boron-doped crystalline silicon," Semiconductor Science and Technology, vol. 14, no. 1, pp. 77-80, 1999.

[14] N. M. Johnson and C. Herring, "Migration of the $\mathrm{H} 2 *$ complex and its relation to $\mathrm{H}^{-}$in n-type silicon," Physical Review B, vol. 43, no. 17, pp. 14297-14300, 1991.

[15] V. P. Markevich and M. Suezawa, "Hydrogen-oxygen interaction in silicon at around $50^{\circ} \mathrm{C}$," Journal of Applied Physics, vol. 83, no. 6, pp. 2988-2993, 1998. 
[16] R. Rizk, P. de Mierry, D. Ballutaud, M. Aucouturier, and D. Mathiot, "Hydrogen diffusion and passivation processes in p- and n-type crystalline silicon," Physical Review B, vol. 44, no. 12, pp. 6141-6151, 1991.

[17] S. J. Pearton, "Diffusion of hydrogen in n-type Si," Materials Science and Engineering B, vol. 23, no. 2, pp. 130-136, 1994.

[18] T. Ichimiya and A. Furuichi, "On the solubility and diffusion coefficient of tritium in single crystals of silicon," International Journal of Applied Radiation and Isotopes, vol. 19, no. 7 , pp. $573-578,1968$.

[19] A. Van Wieringen and N. Warmoltz, "On the permeation of hydrogen and helium in single crystal silicon and germanium at elevated temperatures," Physica, vol. 22, no. 6-12, pp. 849-865, 1956. 


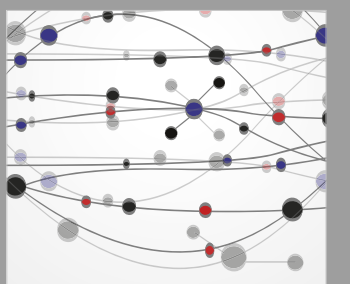

The Scientific World Journal
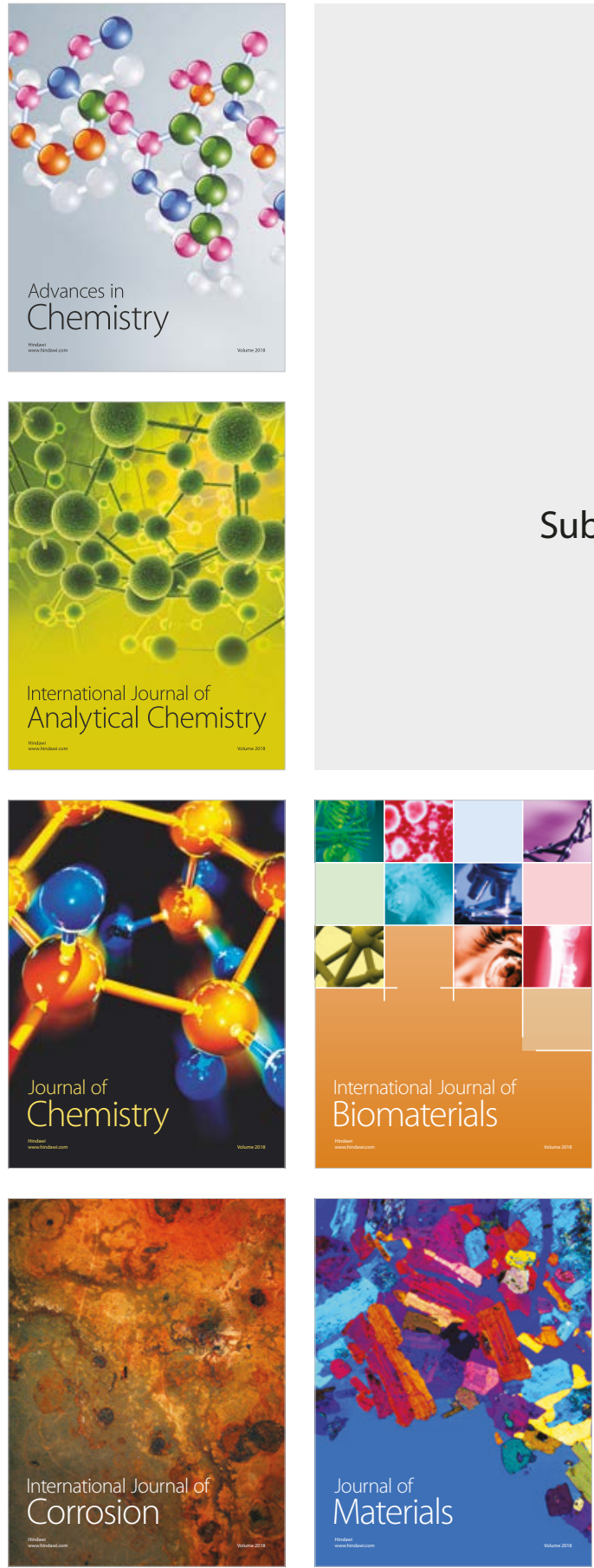

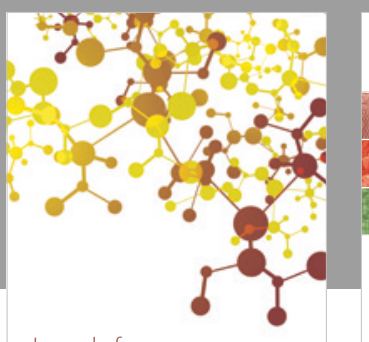

Journal of

Applied Chemistry
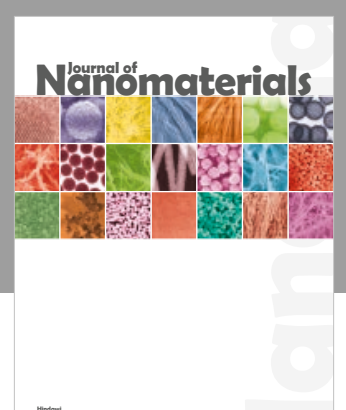

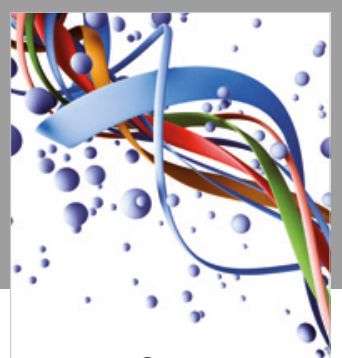

Scientifica

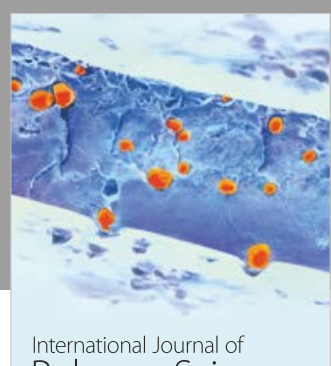

Polymer Science

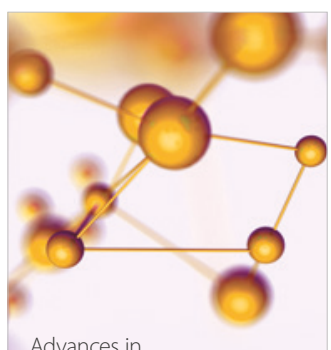

Physical Chemistry
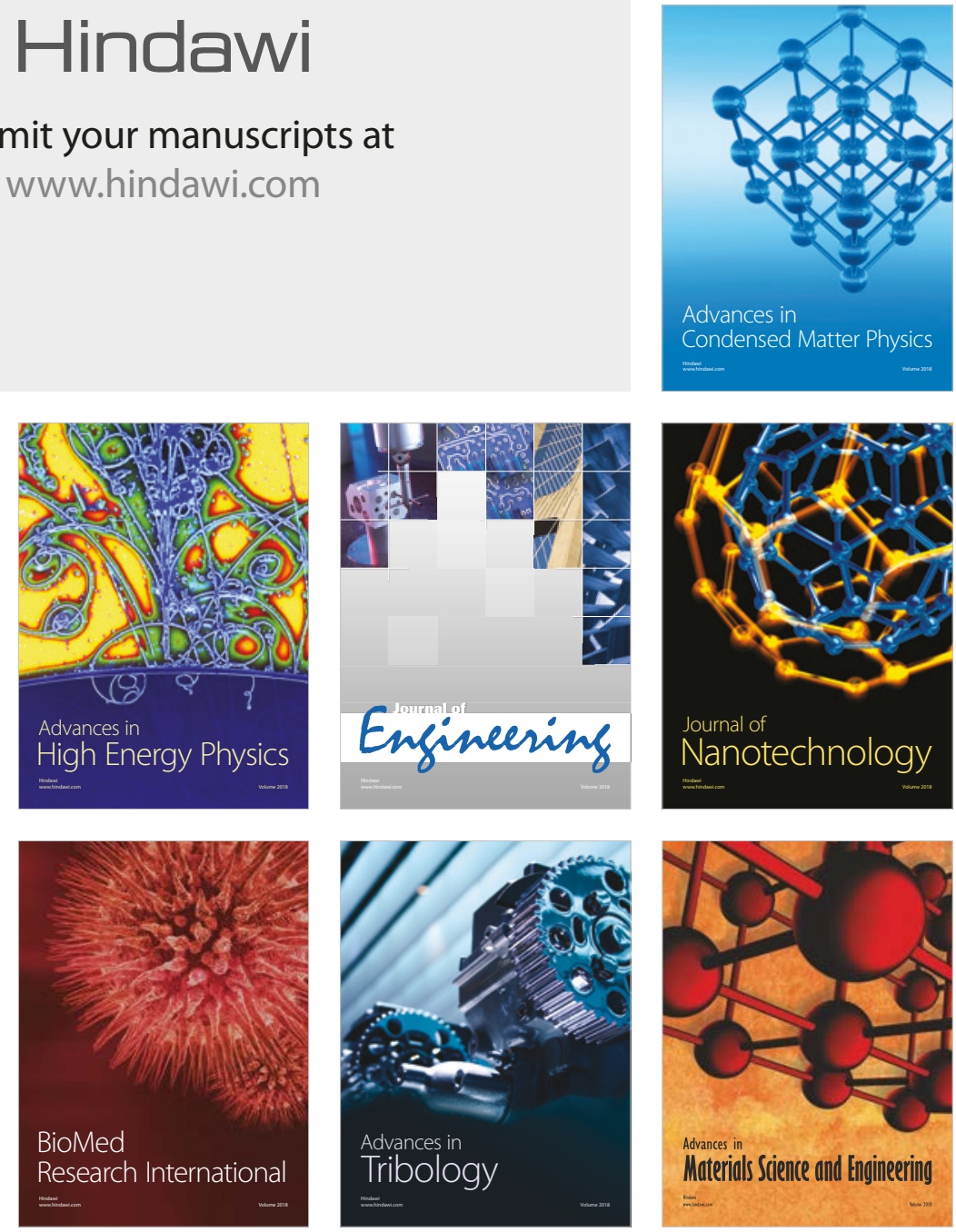